\title{
Association of serum uric acid and gamma-glutamyltransferase with obesity related metabolic derangements in a cohort of children with obesity in Sri Lanka
}

\section{Dinesha M Vidanapathirana', Eresha A Jasinge ${ }^{1}$, Dulani Samaranayake ${ }^{2}$, Pujitha Wickramasinghe ${ }^{3}$}

(Index words: uric acid, gamma-glutamyltransferase, metabolic syndrome, obesity, cardiovascular risk)

\begin{abstract}
Introduction Gamma-glutamyltransferase (GGT) and serum uric acid (UA) are known to be associated with cardiovascular disease in obese children.
\end{abstract}

Objectives To determine the association of serum UA and GGT with components of metabolic syndrome (MetS) in a group of obese children and determine the validity of UA and GGT in predicting MetS.

Methods Cross sectional analytical study was conducted among 205, 5-15 year old obese children. After a 12hour overnight fast, blood was drawn for glucose, lipid profile, alanine aminotransferase (ALT), aspartate aminotransferase (AST), insulin, UA and GGT. Oral glucose tolerance test (OGTT) was done with 2 hour plasma glucose. Height, weight, waist circumference, blood pressure and fat mass were measured. USS of abdomen was performed to assess hepatic steatosis.

Results Chi square test showed statistically significant associations between GGT and UA with triglyceride, insulin resistance (HOMA-IR), AST, ALT, AST/ALT ratio and fatty liver. Additionally UA showed a significant association with the OGTT. With existing cut offs (GGT $>30 \mathrm{U} / \mathrm{L}$ and $\mathrm{UA}>330 \mu \mathrm{mol} / \mathrm{L})$ the sensitivity and specificity of GGT in predicting MetS was $19 \%(95 \% \mathrm{Cl}, 13.63-24.37)$ and $88.4 \%(95 \% \mathrm{Cl}, 84.02-92.78)$ respectively while for UA was $28.6 \%(95 \% \mathrm{Cl}, 22.42-34.78)$ and $80.2 \%(95 \% \mathrm{Cl}$, $74.75-85.65)$ respectively. A new cut off value of $19.5 \mathrm{U} / \mathrm{L}$ (sensitivity $56 \%$ and specificity 55\%) for GGT and 275.5 $\mu \mathrm{mol} / \mathrm{L}$ (sensitivity $61 \%$ and specificity $54 \%$ ) for UA predicted MetS with greater accuracy.

Conclusion GGT and UA are strongly associated with metabolic derangements and these biomarkers are rather weak in predicting MetS.

\section{Introduction}

Adverse effects of health due to obesity is related to excess accumulation of fat in adipose tissue [1]. The exact mechanism of obesity related morbidity is still not well understood [2].

The global incidence of obesity in childhood is estimated to be about 5\% [3]. The prevalence of obesity and overweight among Sri Lankan children in Colombo district was found to be between 14-15\% [4]. The causes attributed to the high incidence of childhood obesity in the developing world include urbanization, unhealthy dietary habits and sedentary behaviour [5].

Metabolic syndrome (MetS) is a state of increase risk of developing cardiovascular diseases, led by insulin resistance. MetS is characterized by central obesity, dysglycaemia, atherogenic dyslipidaemia (high triglycerides and low HDL cholesterol), prothrombotic and procoagulable states. Non alcoholic steatohepatitis (NASH) is a recognized liver complication of obesity. There is evidence to show that cardiovascular risk factors (obesity, diabetes, dyslipidaemia and hypertension), start to track from early stages of life into adulthood [6].

Although serum gamma glutamyltransferase (GGT) and uric acid (UA) are not included as diagnostic criteria of MetS, several studies have shown an association with cardiovascular disease in obese children [7-10].

GGT plays a key role in the transfer of plasma amino acids across the cell membrane into the cell exhibiting intracellular antioxidant property [11]. The mechanism of

Ceylon Medical Journal 2019; 64: 125-132

DOI: http://doi.org/10.4038/cmj.v64i4.8989

${ }^{1}$ Department of Chemical Pathology, Lady Ridgeway Hospital for Children, Colombo, Sri Lanka, ${ }^{2}$ University of Colombo, Faculty of Medicine, Department of Community Medicine, Colombo, Sri Lanka.

Correspondence: DMV, e-mail: <maduri129@yahoo.com>. Received 03 May 2019 and revised version 16 September 2019 accepted 14 December 2019.

This is an open-access article distributed under the terms of the Creative Commons Attribution License, which permits unrestricted use, distribution, and reproduction in any medium, provided the original author and source are credited. 
the antioxidant action is exerted by glutathione metabolism, which results in the formation of cystein, a compound containing thiol [12]. In response to an oxidative stress, elevations in GGT activity is seen which enhances increased transport of reduced glutathione precursors into cells [8].

The final product of purine metabolic pathway is uric acid. Reactive oxygen species produced as by-products in the last two steps of uric acid metabolism, contribute to increased vascular oxidative stress [13]. Furthermore, in oxidative stress conditions, serum uric acid itself can inhibit the function of the endothelium thereby inhibiting the function of nitric oxide [14]. Therefore uric acid could be considered an indicator of oxidative stress as well as a protective antioxidant when its blood levels in humans are within physiological limits [13, 14].

Several studies have indicated that increased UA and GGT are associated with cardio-vascular disease and may be useful in the assessment of individual cardiovascular risk [9,15-20].

There is evidence to show that elevated GGT is associated with insulin resistance, diabetes and MetS where the mechanism of the underlying associations may have to be investigated $[8,21]$.

Studies have shown that elevated UA is associated with diabetes and MetS in early adolescents [22,23].

To date there is no study done, to the best of our knowledge describing the relationship of GGT and UA with cardiovascular risk among obese Sri Lankan children. Associations observed will help us gain knowledge regarding the relationship between GGT, UA with cardiovascular risk factors. GGT and UA are two biochemical tests, freely available in most clinical settings, and it would be useful to make clinicians aware of the usefulness of such simple tools in identifying children who are at risk for cardiovascular disease and using such simple tests would provide scope for primary prevention.

This study aimed at identifying the relationship between GGT and UA with metabolic derangements associated with obesity and identify its ability to detect components of MetS early in its course of development.

\section{Materials and methods}

Two hundred and five, 5-15 year old children with obesity, based on BMI for age greater than 2 standard deviations from the median (WHO-2007 standards), attending the obesity clinic at Lady Ridgeway Hospital, a tertiary care centre hospital in Colombo, were recruited from October 2016 to February 2017. Children with chronic illness, on long term medication, children with an underlying illness that accounts for obesity and children recovering from an acute illness acquired within last 2 weeks were not included. Written informed consent from parent or guardian was obtained and ethical approval was obtained from the Ethics Review Committees of Lady Ridgeway Hospital and Faculty of Medicine, University of Colombo.

All anthropometric measurements (weight, height, waist circumference) and blood pressure were taken adopting standard procedures. Weight was measured with light weight clothing and bare foot. Electronic weighing scale (Soehnle, Soehnle-Waagen GmbH \& Co, Germany) was used and readings were taken to the nearest $0.1 \mathrm{~kg}$. Height was measured by using a stand mounted stadiometer (Surgical and Medical products, Brisbane, Australia). Measurements were taken without shoes to the nearest 0.1 centimeter. Waist circumference was measured midway between the iliac crest and lower rib margin in the mid axillary line at the end of a normal expiration by using a plastic non stretchable flexible tape to the nearest 0.1 centimeter. Seated blood pressure was taken after a 10-minute rest with a mercury sphygmomanometer using appropriate size cuffs.

Fat content of the body was measured by bio electrical impedance (BIA) method, using InBody 230 BIA machine (InBody®, South Korea). The measurements made by this instrument were validated by BIA specific equation [24] and height-weight equation [25] for Sri Lankan children. The study subjects were asked to fast overnight, avoid any vigorous physical activity and urination or defecation at least 2 hours before the procedure. DEXA scans were not performed in these obese children. An experienced radiologist performed an ultra sound scan abdomen (USS Abdomen) to detect fatty liver.

After a 12-hour overnight fast, blood was drawn for glucose, lipid profile, alanine aminotransferase (ALT), aspartate aminotransferase (AST), insulin, UA and GGT. Oral glucose tolerance test (OGTT) was done with anhydrous glucose dose of $1.75 \mathrm{~g} / \mathrm{kg}$ body weight to a maximum of 75 grams and plasma glucose done at 2 hour post dose.

\section{Laboratory assays}

Blood samples were assayed within 6 hours after collection. Samples that could not be analysed on the same day were stored at $-30^{\circ} \mathrm{C}$. Plasma glucose (both fasting plasma glucose and 2 hour OGTT (hexokinase method), triglyceride (TG) (enzymatic colorimetric test without glycerol blanking), high density lipoprotein (HDL) (direct homogenous enzymatic method), ALT and AST (modified International Federation of Clinical Chemistry (IFCC) recommended enzymatic kinetic UV method), GGT (IFCC recommended gamma-glutamyl-3-carboxy-4- 
nitroanlide as substrate method), UA (enzymatic uricase method) were measured on a Beckman Coulter analyzer using standard reagent kits supplied by the manufacturer of the analyzer. Insulin was analysed by chemiluminescent enzyme immunometric assay on Immulite 1000 analyzer. The precision of all these assays was within manufacturer's specifications.

Standard internal and external quality control procedures were carried out using serum based quality control samples to ensure assay validity.

\section{Statistical analysis}

Data were analysed using SPSS ${ }^{\circledR}$ statistical package version 21.0 for windows. Metabolic syndrome among children was diagnosed according to the modified IDF consensus report 2007 [7]. The cut off for homeostatic model assessment for insulin resistance (HOMA-IR) was taken as 2.5 [26]. Prevalence of elevated UA and GGT were given at $95 \%$ confidence intervals.

Chi-square test was used to assess the association of UA and GGT with different metabolic components. Receiver operator characteristic (ROC) curves were created and optimum cut off values maximizing sensitivity and specificity were determined. All analysis were two tailed and level of significance was considered at $\mathrm{p}<0.05$.

\section{Results}

During the period from October 2016 to February 2017 , 210 obese children were recruited to the study. Data of 205 obese children were used in the final analysis.

Table 1 shows the socio demographic characteristics of the sample of obese children. The majority of the participants were girls $(n=144,70.2 \%)$. Most of the children were in the age category of 9 to 12 years $(n=137,66.8 \%)$. The majority of the sample was from the Sinhalese ethnic group $(n=151,73.7 \%)$. Serum GGT was elevated $(>30 \mathrm{U} / \mathrm{L})$ in $16.1 \%$ of the sample (95\% CI, 11.07-21.13). Uric acid was elevated $(>330 \mu \mathrm{mol} / \mathrm{L})$ in $2.9 \%$ of the sample $(95 \%$ CI,0.603 - 5.20).

Table 2 shows the association of serum GGT with different metabolic abnormalities associated with obesity. There were statistically significant associations with triglyceride, AST, ALT, AST/ALT ratio, HOMA-IR and fatty liver.

Table 3 shows the association of UA with different metabolic abnormalities associated with obesity. Among the children with high OGTT, $41.7 \%$ had elevated UA while children with normal OGTT, $22.7 \%$ had elevated UA. This difference was significant $(\mathrm{p}=0.043)$. Similarly significant associations $(\mathrm{p}<0.05)$ were seen with triglyceride, AST, ALT, AST/ALT ratio, HOMA-IR and fatty liver.

Table 4 shows the sensitivity, specificity, positive predictive value and negative predictive value for existing cut off values of GGT and UA.

Figure 1 shows the ROC curve for GGT in predicting MetS. Area under the curve was 0.584 and was significant. A cut off of 19.5 U/L was obtained with a reasonable level of sensitivity $(56 \%)$ and specificity of $(55 \%)$.

Figure 2 shows the ROC for UA in predicting MetS. Area under the curve for UA in predicting MetS was 0.579, but it was not statistically significant. A cut off value of $275.50 \mu \mathrm{mol} / \mathrm{L}$ was obtained with a reasonable level of sensitivity $(61 \%)$ and specificity of $(54 \%)$.

Table 1. Socio-demographic characteristics of the sample

\begin{tabular}{llc}
\hline Socio-demographic characteristics & Frequency (\%) \\
\hline \multirow{2}{*}{ Age } & $5-8 \mathrm{yr}$ & $50(24.4)$ \\
& $9-12 \mathrm{yr}$ & $137(66.8)$ \\
& $13-15 \mathrm{yr}$ & $18(8.8)$ \\
& & \\
Gender & Male & $61(29.8)$ \\
& Female & $144(70.2)$ \\
& & \\
Ethnicity & Sinhalese & $151(73.7)$ \\
& Muslim & $36(17.6)$ \\
& Tamil & $18(8.8)$ \\
\hline
\end{tabular}


Table 2. Association of GGT with metabolic abnormalities

\begin{tabular}{|c|c|c|c|c|}
\hline Metabolic & & & vel & \\
\hline & & High & Normal & $p$ \\
\hline FBS & High & $5(21.7 \%)$ & $18(78.3 \%)$ & \\
\hline & Normal & $28(15.4 \%)$ & $154(84.6 \%)$ & 0.631 \\
\hline OGTT & High & $6(25 \%)$ & $18(75 \%)$ & \\
\hline & Normal & $27(14.9)$ & $154(85.1 \%)$ & 0.333 \\
\hline Triglyceride & High & $14(32.6 \%)$ & $29(67.4 \%)$ & \\
\hline & Normal & $19(11.7 \%)$ & $143(88.3 \%)$ & 0.001 \\
\hline HDL & Low & $19(18.1 \%)$ & $86(81.9 \%)$ & \\
\hline & Normal & $14(14.0 \%)$ & $86(86 \%)$ & 0.425 \\
\hline$* \mathrm{DBP}$ & High & $0(0 \%)$ & $6(100 \%)$ & \\
\hline & Normal & $33(16.6 \%)$ & $166(83.4 \%)$ & 0.599 \\
\hline $\mathrm{WC}$ & High & $33(16.4 \%)$ & $168(83.6 \%)$ & \\
\hline & Normal & $0(0 \%)$ & $4(100 \%)$ & 0.843 \\
\hline AST & High & $18(40.9 \%)$ & $26(59.1 \%)$ & \\
\hline & Normal & $15(9.3 \%)$ & $146(90.7 \%)$ & 0.000 \\
\hline ALT & High & $24(47.1 \%)$ & $27(52.9 \%)$ & \\
\hline & Normal & $9(5.9 \%)$ & $144(94.1 \%)$ & 0.000 \\
\hline AST/ALT & $>1$ & $11(8.6 \%)$ & $117(91.4 \%)$ & \\
\hline Ratio & $<1$ & $22(28.9 \%)$ & $54(71.1 \%)$ & 0.000 \\
\hline HOMA-IR & High & $27(24.8 \%)$ & $82(75.2 \%)$ & \\
\hline & Normal & $6(6.4 \%)$ & $88(93.6 \%)$ & 0.000 \\
\hline USS & Fatty Liver & $16(30.8 \%)$ & $36(69.2 \%)$ & \\
\hline & Normal & $3(8.1 \%)$ & $34(91.9 \%)$ & 0.010 \\
\hline Metabolic syndrome & Present & $23(19.3 \%)$ & $96(80.7 \%)$ & 0.139 \\
\hline & Absent & $10(11.6 \%)$ & $76(88.4 \%)$ & \\
\hline
\end{tabular}

*DBP - Diastolic Blood Pressure

Table 3. Association of uric acid (UA) with metabolic abnormalities

\begin{tabular}{|c|c|c|c|c|}
\hline \multicolumn{2}{|c|}{ Metabolic parameter } & \multicolumn{2}{|c|}{ Uric Acid level } & \multirow[b]{2}{*}{$p$} \\
\hline & & High & Normal & \\
\hline FBS & $\begin{array}{l}\text { High } \\
\text { Normal }\end{array}$ & $\begin{array}{c}5(21.7 \%) \\
46(25.3 \%)\end{array}$ & $\begin{array}{c}18(78.3 \%) \\
136(94.7 \%)\end{array}$ & 0.712 \\
\hline OGTT & $\begin{array}{l}\text { High } \\
\text { Normal }\end{array}$ & $\begin{array}{l}10(41.7 \%) \\
41(22.7 \%)\end{array}$ & $\begin{array}{c}14(58.3 \%) \\
140(77.3 \%)\end{array}$ & 0.043 \\
\hline Triglyceride & $\begin{array}{l}\text { High } \\
\text { Normal }\end{array}$ & $\begin{array}{l}17(39.5 \%) \\
34(21 \%)\end{array}$ & $\begin{array}{l}26(60.5 \%) \\
128(79 \%)\end{array}$ & 0.012 \\
\hline HDL & $\begin{array}{l}\text { Low } \\
\text { Normal }\end{array}$ & $\begin{array}{l}29(27.6 \%) \\
22(22 \%)\end{array}$ & $\begin{array}{l}76(72.4 \%) \\
78(78 \%)\end{array}$ & 0.352 \\
\hline DBP & $\begin{array}{l}\text { High } \\
\text { Normal }\end{array}$ & $\begin{array}{c}2(33.3 \%) \\
49(24.6 \%)\end{array}$ & $\begin{array}{c}4(66.7 \%) \\
150(75.4 \%)\end{array}$ & 0.994 \\
\hline $\mathrm{WC}$ & $\begin{array}{l}\text { High } \\
\text { Normal }\end{array}$ & $\begin{aligned} 50 & (24.9 \%) \\
1 & (25 \%)\end{aligned}$ & $\begin{array}{c}151(75.1 \%) \\
3(75 \%)\end{array}$ & 1.000 \\
\hline AST & $\begin{array}{l}\text { High } \\
\text { Normal }\end{array}$ & $\begin{array}{l}21(47.7 \%) \\
30(18.6 \%)\end{array}$ & $\begin{array}{r}23(52.3 \%) \\
131(81.4 \%)\end{array}$ & 0.000 \\
\hline ALT & $\begin{array}{l}\text { High } \\
\text { Normal }\end{array}$ & $\begin{array}{l}24(47.1 \%) \\
27(17.6 \%)\end{array}$ & $\begin{array}{r}27(52.9 \%) \\
126(82.4 \%)\end{array}$ & 0.000 \\
\hline $\begin{array}{l}\text { AST/ALT } \\
\text { Ratio }\end{array}$ & $\begin{array}{l}>1 \\
<1\end{array}$ & $\begin{array}{ll}20 & (15.6 \%) \\
31 & (40.8 \%)\end{array}$ & $\begin{array}{r}108(84.4 \%) \\
45(59.2 \%)\end{array}$ & 0.000 \\
\hline USS & Fatty Liver & $21(40.4 \%)$ & $31(59.6 \%)$ & \\
\hline & Normal & $6(16.2 \%)$ & $31(83.8 \%)$ & 0.015 \\
\hline HOMA-IR & $\begin{array}{l}\text { High } \\
\text { Normal }\end{array}$ & $\begin{array}{l}35(32.1 \%) \\
14(14.9 \%)\end{array}$ & $\begin{array}{l}74(67.9 \%) \\
80(85.1 \%)\end{array}$ & 0.004 \\
\hline Metabolic syndrome & $\begin{array}{l}\text { Present } \\
\text { Absent }\end{array}$ & $\begin{array}{l}34(28.6 \%) \\
17(19.8 \%)\end{array}$ & $\begin{array}{l}85(71.4 \%) \\
69(80.2 \%)\end{array}$ & 0.15 \\
\hline
\end{tabular}


Table 4. Validity indicators for existing cut off for GGT and UA in predicting MetS

\begin{tabular}{lll}
\hline Validity Indicator & $G G T>30 \mathrm{U} / \mathrm{L}$ & $\begin{array}{l}\text { Uric acid }>330 \mu \mathrm{mol} / \mathrm{L} \\
(5.5 \mathrm{mg} / \mathrm{dL})\end{array}$ \\
\hline Sensitivity & $19 \%(13.63-24.37)^{*}$ & $28.6 \%(22.42-34.78)^{*}$ \\
Specificity & $88.4 \%(84.02-92.78)^{*}$ & $80.2 \%(74.75-85.65)^{*}$ \\
Positive predictive value & $69.5 \%(63.20-75.80)^{*}$ & $66.66 \%(60.21-73.11)^{*}$ \\
Negative predictive value & $44.2 \%(47.66-40.74)^{*}$ & $44.8 \%(43.80-51.60)^{*}$ \\
\hline
\end{tabular}

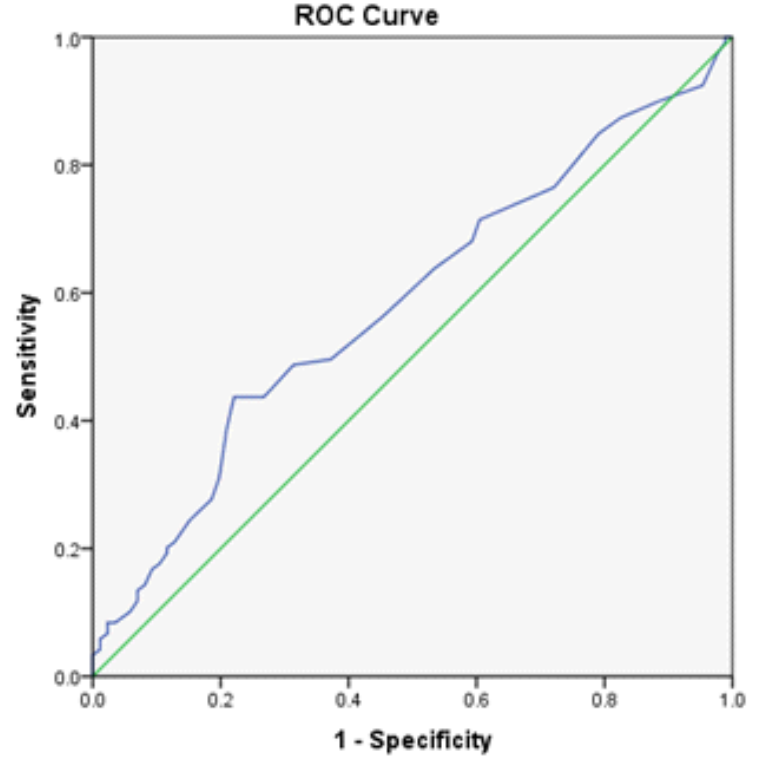

Diagonal segments are produced by ties.

Figure 1. ROC curve for GGT in predicting MetS

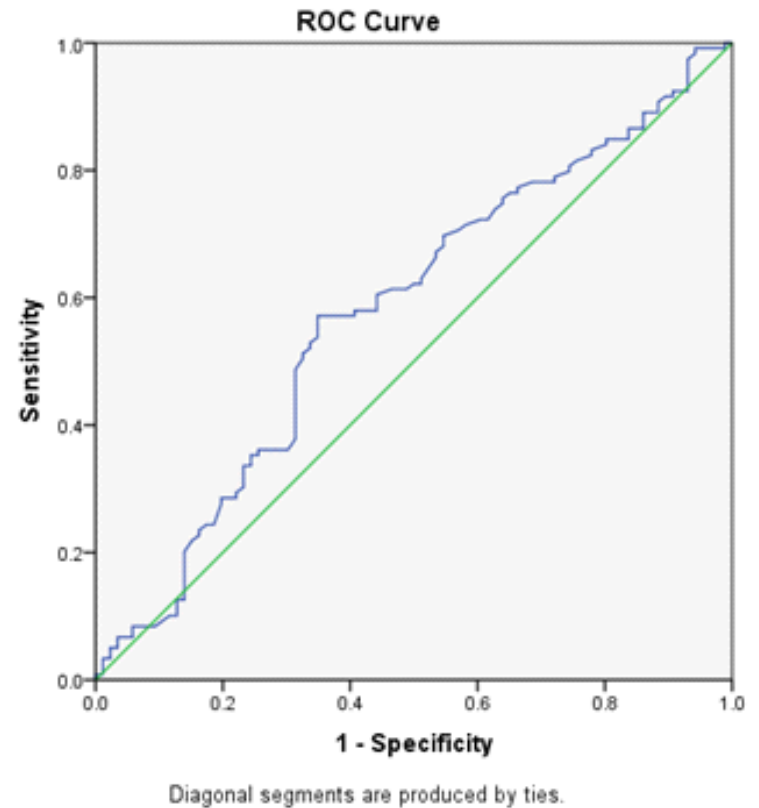

Figure 2. ROC for UA in predicting MetS

\section{Discussion}

Our study revealed that the prevalence of hyperuricemia among obese children is $2.9 \%$ (95\% CI, 0.603 - 5.20). This is relatively low compared to other published studies. The reported rates of hyperuricemia among obese children and adolescents published in the literature differ widely ranging from $15.6 \%$ to $35.7 \%$ [26-28]. A study done in Brazil showed the prevalence of hyperuricemia to be $12.4 \%$. But both obese and overweight children have been considered and sample size is smaller than ours (129 children) [10]. A study done in Spain shows a relatively higher prevalence $(53 \%)$ of hyperuricemia. However in this study also both overweight and obese categories have been considered with a small sample size (148 children) [29]. Differences in the prevalence rate is because of the difficulty in obtaining reference values for UA in children which is highly dependent on age and also because unified diagnostic criteria for MetS have been established only recently [30]. There is limited data on the prevalence of the state of GGT in obese children. The prevalence of elevated GGT in our study was $16.1 \%$ (95\% CI, 11.07-21.13).

Out of the 5 components of MetS, our data have demonstrated a strong association of serum UA with OGTT and triglycerides. A study done in USA with 1370 subjects showed a significant association of UA with hypertriglyceridaemia, hyperglycaemia and abdominal obesity [31]. Our study didn't show a significant association of UA with diastolic blood pressure, abdominal obesity, fasting plasma glucose and HDL. The finding of hyperglycemia in young children is unusual, as the more frequent manifestation of glucose metabolism is insulin resistance which is a compensatory mechanism prior to the development of MetS [32]. In our study though we couldn't establish a positive association of serum UA with blood pressure several studies have shown 4 fold risk of developing hyperuricemia in individuals with high SBP [33]. A study done in Japan on 1027 obese children demonstrated similar findings to our study with no statistically significant associations with DBP and waist circunference [30]. Furthermore the findings of a study done in Spain is similar to our study findings showing a strong association 
with OGTT and failing to do so with fasting blood glucose [29]. Our study also was able to demonstrate a statistically significant association between hyperuricemia with AST, ALT, AST/ALT ratio and fatty liver.

In our study elevated GGT showed a significant association with triglyceride, AST, ALT, AST/ALT ratio and fatty liver. We could not elicit a statistically significant association with FPG, 2h RPG of OGTT, BP, waist circumference and HDL. There are few studies done in obese children to see the association with GGT. However, a study done in India on 100 obese adults shows a significant association with FPG, BP, waist circumference, HDL and triglycerides [34].

In our study we also demonstrated the sensitivity, specificity, positive predictive value and negative predictive value for existing cut off values for GGT and UA in detecting MetS. GGT cut off was taken as > 30U/L [35]. The sensitivity of GGT in predicting MetS was low (19\% CI13.63 - 24.37) but specificity was high $88.4 \%$ (84.0292.78). Positive predictive value was $69.5 \%$ (63.20-75.80) with a negative predictive value of $44.2 \%$ (47.66-40.74).

The existing UA cut off to predict MetS was taken as $>330 \mu \mathrm{mol} / \mathrm{L}$ [36]. The sensitivity of serum UA in predicting MetS was low 28.6\% (22.42-34.78) and specificity was high $80.2 \%$ (74.75-85.65). Positive predictive value was $66.7 \%$ (60.21-73.11) with a negative predictive value of $44.8 \%$ $(38-51.60)$.

The area under the curve (AUC) for GGT in predicting MetS was 0.584, which was significant. A cut off of $19.5 \mathrm{U} /$ $\mathrm{L}$ was obtained with a reasonable level of sensitivity (56\%) and specificity of $(55 \%)$. Interestingly the cut off point for 'high' GGT is still within the normal laboratory reference range. A study done in Turkey on 442 obese adults showed an optimum cut off value of 20.5 IU for women and 26.5 IU for men showing 'high' GGT to be still within reference range [37]. There is much debate on the current reference intervals used in most laboratories for GGT as many studies have shown increased mortality in patients with serum GGT activities even within the current reference interval [11]. Therefore in this aspect the clinicians should be aware of the false sense of security that all is well, and no further action is required, which may not be the situation in most cases.

Uric acid level, from which a diagnosis of MetS was most likely, corresponded to $275.50 \mu \mathrm{mol} / \mathrm{L}$ in our sample (AUC 0.579, sensitivity: 61\% and specificity 54\%). Our study found similar results reported by other studies done in children although there are few published data on obese populations to investigate the relationship between hyperuricemia and MetS. A study done in USA among 142 obese or overweight children, a diagnosis of MetS corresponded to $324 \mu \mathrm{mol} / \mathrm{L}$ (AUC 0.66, sensitivity: 64\% and specificity 62\%) [27]. There are inter-gender differences and racial ethnic differences affecting UA cut offs as shown in some studies [38]. Inter-gender differences are due to females having a lower level of UA than males which is most likely due to uricosuric effect of estrogen [36]. Racial ethnic differences may have contributed to our cut off value that predict MetS, but future studies are of need to study extensively in this aspect.

Our study had limitations. First UA and GGT were measured only once. Therefore intra-individual variations would have had an impact on the results. Furthermore information on lifestyle of the children recruited was lacking. The habit of frequent eating of purine rich food may cause hyperuricemia and MetS simultaneously.

In spite of these limitations this study is, as far as we know, the first study done in Sri Lanka to see the association of serum UA and GGT with components of MetS in obese children. GGT and UA are strongly associated with many metabolic derangements however, the usefulness of these biomarkers in predicting MetS needs to be explored further. The knowledge gained regarding the relationship between GGT and UA with cardiovascular risk factors would raise awareness among clinicians to identify the youth who are at risk for primary prevention of cardiovascular disease. Easy availability and inexpensiveness of these markers favour the clinician to use these markers freely.

\section{Acknowledgements}

We thank Prof. Sumedha Wijeyrathna, Mrs. A.M. Warnakulasuriya, Mr. H.M.D.N. Herath, Ms. T.W.A.E.N. Kumari from Department of Gynaecology and Obstetrics, Ms. S.M.T.H. Senevirathna, Ms. T.K.G. Rathnayaka, Mr. S.D.D. Dissanayaka, Mr. D.R.S. Jayasinghe from Department of Paediatrics, Faculty of Medicine, University of Colombo and laboratory technical staff of Vindana Reproductive Center, Colombo and Department of Chemical Pathology, Lady Ridgeway Hospital for Children for their enormous support in processing and analysis of the samples.

The staff of the Radiology Department of the Lady Ridgeway Hospital for Children in performing the ultra sound scans and the phlebotomist of the Professorial Paediatric Unit at Lady Ridgeway Hospital.

We also thank Biomed Scientific Pvt Ltd for supplying reagents free of charge.

\section{Conflicts of interest}

There are no conflicts of interest. 


\section{References}

1. Dehghan M, Akhtar-Danesh N, Merchant AT. Childhood obesity, prevalence and prevention. Nutr J. 2005; 4(1): 1-8.

2. Rathnayake KM, Satchithananthan A, Mahamithawa S, Jayawardena R. Early life predictors of preschool overweight and obesity: a case-control study in Sri Lanka. $B M C$ Public Health 2013; 13(1): 1-6.

3. GBD 2015 obesity collaborators, Afshin A, Forouzanfar MH, Reitsma MB, Sur P, Estep K, et al. Health effects of overweight and obesity in 195 countries over 25 years. $N$ Engl J Med. 2017; 377(1): 13-27.

4. Wickramasinghe VP, Lamabadusuriya SP, Cleghorn GJ, Davies PS. Validity of currently used cutoff values of body mass index as a measure of obesity in Sri Lankan children. Ceylon Med J 2009; 54(4): 114-9.

5. Alberti KGMM, Zimmet P, Shaw J. Metabolic syndromea new world-wide definition. A Consensus Statement from the International Diabetes Federation. Diabetic Med. 2006; 23(5): 469-80.

6. Srinivasan SR, Bao W, Wattigney WA, Berenson GS. Adolescent overweight is associated with adult overweight and related multiple cardiovascular risk factors: the Bogalusa Heart Study. Metab Clin Exp. 1996; 45(2): 235-40.

7. Ishiro M, Takaya R, Mori Y, Takitani K, Kono Y, Okasora $\mathrm{K}$, et al. Association of uric acid with obesity and endothelial dysfunction in children and early adolescents. Ann Nutr Metab. 2013; 62(2): 169-76.

8. Lee SY, Sung E, Chang Y. Elevated Serum GammaGlutamyltransferase is a Strong Marker of Insulin Resistance in Obese Children. Int J Endocrinol 2013; 2013: 6 .

9. Wang ZN, Li P, Jiang RH, Li L, Li X, Li L, et al. The association between serum uric acid and metabolic syndrome among adolescents in northeast China. Int J Clin Exp Med. 2015; 8(11): 21122-9.

10. Cardoso AS, Gonzaga NC, Medeiros CC, Carvalho DF. Association of uric acid levels with components of metabolic syndrome and non-alcoholic fatty liver disease in overweight or obese children and adolescents. J Pediatr (Rio J). 2013; 89(4): 412-8.

11. Bulusu S, Sharma M. What does serum gammaglutamyltransferase tell us as a cardiometabolic risk marker? Ann Clin Biochem 2016; 53(3): 312-32.

12. Lee DH, Blomhoff R, Jacobs DR, Jr. Is serum gamma glutamyltransferase a marker of oxidative stress? Free Radic Res. 2004; 38(6): 535-9.

13. Pasalic D, Marinkovic N, Feher-Turkovic L. Uric acid as one of the important factors in multifactorial disorders facts and controversies. Biochemia Medica 2012; 22(1): 63-75.

14. Glantzounis GK, Tsimoyiannis EC, Kappas AM, Galaris DA. Uric acid and oxidative stress. Curr Pharm Des 2005; 11(32): 4145-51.

15. Kong AP, Choi KC, Ho CS, Chan MH, Ozaki R, Chan CW, et al. Associations of uric acid and gammaglutamyltransferase (GGT) with obesity and components of metabolic syndrome in children and adolescents. Pediatr Obes. 2013; 8(5): 351-7.

16. Lee D-J, Choi J-S, Kim K-M, Joo N-S, Lee S-H, Kim K-N. Combined effect of serum gamma-glutamyltransferase and uric acid on Framingham risk score. Arch Med Res. 2014; 45(4): $337-42$.

17. Lee DH, Jacobs DR, Jr., Gross M, Kiefe CI, Roseman J, Lewis CE, et al. Gamma-glutamyltransferase is a predictor of incident diabetes and hypertension: the Coronary Artery Risk Development in Young Adults (CARDIA) Study. Clin Chem. 2003; 49(8): 1358-66.

18. Sagodi L, Feher V, Kiss-Toth E, Almasi A, Barkai L. [Metabolic complications of obesity during adolescence, particularly regarding elevated uric acid levels]. Orvosi hetilap. 2015; 156(22): 888-95.

19. Feig DI, Johnson RJ. The Role of Uric Acid in Pediatric Hypertension. J Ren Nutr. 2007; 17(1): 79-83.

20. Strasak AM, Kelleher CC, Klenk J, Brant LJ, Ruttmann E, Rapp $\mathrm{K}$, et al. Longitudinal change in serum gammaglutamyltransferase and cardiovascular disease mortality: a prospective population-based study in 76,113 Austrian adults. Arterioscler Thromb Vasc Biol. 2008; 28(10): 1857-65.

21. Jarcuska P, Janicko M, Drazilova S, Senajova G, Veseliny E, Fedacko J, et al. Gamma-glutamyl transpeptidase level associated with metabolic syndrome and proinflammatory parameters in the young Roma population in eastern Slovakia: a population-based study. Cent Eur J Public Health. 2014; 22 Suppl: S43-50.

22. Oyama C, Takahashi T, Oyamada M, Oyamada T, Ohno T, Miyashita M, et al. Serum uric acid as an obesity-related indicator in early adolescence. Tohoku J Exp Med. 2006; 209(3): 257-62.

23. Rasheed K, Kapusta DR, Reisin E. Potential Role of Uric Acid in Metabolic Syndrome, Hypertension, Kidney Injury, and Cardiovascular Diseases: Is It Time for Reappraisal? Curr Hypertens Rep. 2013; 15(3): 175-81.

24. Wickramasinghe VP, Cleghorn GJ, Lamabadusuriya SP and Davies PSW. Assessment of body composition in Sri Lankan children: validation of a bioelectrical impedance prediction equation. Eur J Clin Nutr. 2008; 62(10): 1170-7.

25. Wickramasinghe VP, Lamabadusuriya SP, Cleghorn GJ, Davies PSW. Development of Height-Weight based equation for Assessment of body composition in Sri Lankan children. Indian J Pediatr 2010; 77(2): 155-60.

26. Bokor S, Frelut ML, Vania A, Hadjiathanasiou CG, Anastasakou M, Malecka-Tendera E, et al. Prevalence of metabolic syndrome in European obese children. Int $J$ Pediatr Obes. 2008; 3 Suppl 2: 3-8.

27. Saito I, Mori M, Shibata H, Hirose H, Tsujioka M, Kawabe H. Prevalence of metabolic syndrome in young men in Japan. Arterioscler Thromb. 2007; 14(1): 27-30.

28. Pacifico L, Cantisani V, Anania C, Bonaiuto E, Martino F, Pascone R, et al. Serum uric acid and its association with metabolic syndrome and carotid atherosclerosis in obese children. Eur J Endocrinol 2009; 160(1): 45-52. 
29. Civantos Modino S, Guijarro de Armas MG, Monereo Mejias S, Montano Martinez JM, Iglesias Bolanos P, Merino Viveros M, et al. Hyperuricemia and metabolic syndrome in children with overweight and obesity. Endocrinol Diabetes Nutr. 2012; 59(9): 533-8.

30. Tang L, Kubota M, Nagai A, Mamemoto K, Tokuda M. Hyperuricemia in obese children and adolescents: the relationship with metabolic syndrome. Pediatr Rep. 2010; 2(1): e12.

31. Earl S ford, Chaoyang Li. Serum concentrations of uric acid and the metabolic syndrome among US children and adolescents. Circulation 2007; 115: 2526-32.

32. Quinones Galvan A, Natali A, Baldi S, Frascerra S, Sanna G, Ciociaro D, et al. Effect of insulin on uric acid excretion in humans. Am J Physio.1995; 268(1Pt1): E1-5.

33. Choi HK, Ford ES. Prevalence of the metabolic syndrome in individuals with hyperuricemia. Am J Med. 2007; 120(5): 442-7.
34. Latha PJ GS. Correlation of Serum Gamma Glutamyl Transferase with Atherogenic Dyslipidemia in Obese Individuals. Sch J App Med Sci. 2015; 3(1F): 387-91.

35. Paediatric test reference values. Mayo clinic laboratories. www.mayomedicallaboratories.com (accessed on 10th Aug, 2016).

36. Roberts WL, McMillin GA, Burtis CA. Reference information for the clinical laboratory. In: Burtis $\mathrm{C}$, Aswood E, Bruns D. Tietz textbook of clinical chemistry and molecular diagnostics. 5th ed. Saunders; 2012. p.2131-88.

37. Kasapoglu B, Turkay C, Bayram Y, Koca C. Role of GGT in diagnosis of metabolic syndrome: a clinic-based crosssectional survey. Indian J Med Res. 2010; 132: 56-61.

38. DeBoer MD, Dong L, Gurka MJ. Racial/Ethnic and Gender Differences in the Relationship between Uric Acid and Metabolic Syndrome in Adolescents: An Analysis of NHANES 1999-2006. Metab Clin Exp. 2012; 61(4): 554-61. 